\title{
Parents' Knowledge and Attitudes When Choosing Their Children's School Bag: an Introductory Study
}

\author{
Dijana Laštro, ${ }^{1}$ Mirsad Muftić, ${ }^{2}$ Nenad Ponorac, ${ }^{3}$ Dubravko Bokonjić4
}

\begin{abstract}
Background/Aim: A school bag is a device whose purpose is to store things that are necessary for a child in performing daily productive activities. The aim of the research was to examine how much parents are informed about the school bag and which specifications are crucial when choosing a school bag for their children.

Material and methods: The prospective study included 150 parents of students aged 11 to 12 from Banja Luka. For the purposes of the research, a questionnaire with closed and open questions was used.

Results: More than $97 \%$ of the surveyed parents belonged to the age range of 30 to 49 years. The largest number of surveyed parents have had secondary education 44 $\%$, but the number of university-educated parents was also very high $39.3 \%$. Ninety-six percent of students used a backpack. School bags in $97.4 \%$ of cases were purchased in stores. Only in $10 \%$ of cases, school bags fully meet the basic criteria. In the remaining $90 \%$ of cases, there was an absence of at least one or more desired characteristics. Using the Chi-squared test $\left(\chi^{2}=245.45 ; \mathrm{p}<0.001\right)$, a significant difference between the desired and the achieved result was statistically proven. $77.3 \%$ of parents did not receive information about the school bag. Salespeople (11.3\%), other parents and friends ( $9.3 \%$ ) were the main source of information before purchasing a school bag. In the future, $54 \%$ of parents would like to get information about the school bag through lectures and practical workshops for children and parents.

Conclusion: Greater information enables adequate selection and reduces the possibility of marketing tricks and influences on consumers when choosing the desired product such as a school bag. Parents have an important role to play in ensuring unhindered growth and development during the educational process and in raising children's awareness and supervision of the proper use of the school bag.
\end{abstract}

Key words: Schoolbag; Parents; Knowledge; Awareness.
(1) Institute for Physical Medicine and Rehabilitation "Dr Miroslav Zotović", Banja Luka, the Republic of Srpska, Bosnia and Herzegovina.

(2) Faculty of Health Studies, University of Sarajevo, the Federation of Bosnia and Herzegovina, Bosnia and Herzegovina.

(3) Department of Physiology, Faculty of Medicine, University of Banja Luka, Banja Luka, the Republic of Srpska, Bosnia and Herzegovina.

(4) Medical Faculty of the Military Medical Academy, University of Defence, Belgrade, Serbia.

Correspondence:

DIJANA LAŠTRO

E: dijana.lastro@med.unibl.org

\section{ARTICLE INFO}

Received: 24 May 2021 Revision received: 21 June 2021 Accepted: 21 June 2021

\section{Introduction}

Carrying a school bag is a common way of carrying teaching aids and accessories that are necessary for a child to perform daily productive activities. Numerous studies have reported side effects associated with school bag use, prevalence, and risk factors such as back pain in younger students. ${ }^{1-3}$
According to a University of Boston study, about $85 \%$ of students report discomfort and pain associated with backpack use on their own. Being overweight can lead to health problems in the short and long term. Improper use of backpacks can lead to muscle imbalance that could turn into 
chronic neck and back pain. ${ }^{4}$ A systematic review by Balamurugan (2017) reports that a school bag, that is approximately $10-15 \%$ of body weight can cause overload of the cervical spine and upper limbs, when burdened by weight in the thoracic spine. ${ }^{5}$ Weight has a significant effect on the centre of gravity of the body taking into account appropriate carrying techniques. Different bag carrying techniques are a significant factor influencing the posture and gait of students between of ages 11 - 13 years.

Studies have reported that there is no difference in lateral spinal deviation between two-strap backpacks and students without a bag, however, the belt on the school bag reduces the strain on the back, neck and shoulders. ${ }^{6-8}$ Carrying a school bag has significant biomechanical, physiological and adverse effects on the wearer, especially with loads greater than $10 \%$ of the student's body weight. Such effects may include changes in posture (eg, changes in spinal posture, lumbosacral angles, and thoracic kyphosis), gait, increased physical discomfort, muscle activity, and increased respiratory rate. ${ }^{9}$ Nevertheless, concerns have been raised about the possible harmful consequences of using a school bag, especially related to overweight, back position and suboptimal design aspects such as uncomfortable shoulder straps and the absence of shoulder straps. ${ }^{10-13}$

American Association for Occupational Therapy, The American Academy of Orthopaedic Surgeons and the International Association of Paediatric Chiropractors suggests that the load should not exceed $10 \%$, the American Association of Physical Therapy suggests $15 \%$, and the American Association of Chiropractors 5-10 \% of body weight. ${ }^{14}$ A comprehensive understanding of the recommended measures is necessary to achieve the desired effect. Authors Dianat and Karimi (2014) concluded in the study that parental awareness should play an important role in changing children's school bag carrying habits, and especially in reducing the weight of the burden they carry. This highlights the need to incorporate guidelines and recommendations into practice to ensure that the health and safety of schoolchildren is not compromised when using a school bag. ${ }^{15}$ Although the American Association of Occupational Therapists (AOTA, 2014) has issued guidelines for the proper use of a school bag, in our country there is a lack of such prevention programs. $^{16}$
The goal of this research was to examine how much parents are informed about the school bag and what specifications are crucial when choosing a school bag for their children.

\section{Methods}

The research was a prospective study. Using the cluster sampling method, the study included 1507 parents of students aged 11 to 12, of seven primary city schools from Banja Luka. After meeting the criteria for inclusion and testing students with a physical activity test (The Physical Activity Questionnaire for Older Children, PAQ-C), ${ }^{17,18}$ respondents with their parents entered the study successively and were divided into three groups: insufficiently physically active, moderately, and highly physically active children. Sampling was performed until the number of 150 respondents of both sexes and their parents was filled.

Criteria for inclusion: children of older primary school age 11-12, both sexes, children who have signed written consent of a parent or legal representative, children who have agreed and signed written consent to participate in the research and children who have the ability to self-ambulance.

Exclusion criteria: children with intellectual disabilities, epilepsy, cerebral palsy, hemiparesis, diabetes mellitus, heart and circulatory diseases, respiratory diseases, children with a history of fractures or injuries of the lower extremities in the past year, children who used a mobility aid, fatigue, pain and inability to adapt to the work of the zebris strip.

The research was approved by the Ministry of Education and Culture of the Republic of Srpska (Approval Certificate No 07.041/059-3292/18 dated 17 December 2018 and No 07.041/059-2436/19 dated 25 September 2019 and the Ethics Committee of the Medical Faculty of the University of Banja Luka (Approval Certificate No 18/14.27/19 dated 1 July 2019 and No 18/4.27-1/20 dated 5 February 2020). All respondents and parents gave their voluntary consent, which in addition to the oral explanation was also contained in the informed consent for parents and students and written information for parents and students. The research was conducted during the school year 2019/2020 and 2020/2021. 
For the purposes of the research, a survey questionnaire for parents based on previous research was used and adapted to the needs of the research itself. $^{19}$ The survey questionnaire is designed to assess parents' awareness of the factors associated with carrying a school bag as well as which specifications are crucial when choosing a school bag. The questionnaire consisted of 37 questions that were mostly with one or more choice answers closed $(n=34)$ and open type $(n=3)$. From the survey questionnaire, items related to information on demographic data and family structure, school bag design, type, weight, importance of school bag characteristics, place of school bag procurement, availability and request for use of information and parental education were selected.

The parents were interviewed at the school and at the Institute for Physical Medicine and Rehabilitation "Dr Miroslav Zotović" in Banja Luka. The research was conducted by a research team consisting of the main researcher, occupational therapist-physiotherapist and trainee occupational therapist.

Complete statistical analysis of data was done with the statistical software package, SPSS Statistics 18. Most of the variables were presented in a text and table as frequency (\%) of certain categories. Statistical significance between groups (categorical data) was tested by Chi-squared test. In case of continuous data, variables were presented as mean value \pm standard deviation (SD). All analyses were estimated at minimum $\mathrm{p}<0.05$ level of statistical significance.

\section{Results}

The results of the descriptive analysis of the basic characteristics of the school bag that children had, and the compliance of the desired and realised characteristics of the bag are shown in the table (Table 3 and 4), as well as demographic and socio-economic characteristics of the sample, school bag procurement (Table 1 and 2), and graphically (Figure 1, 2, 3) the importance of school bag characteristics, sources of information that parents have used and would like to use in the future about the school bag. The values of the results of the descriptive statistics are shown in absolute numbers and percentages (\%).
Table 1: Basic demographic characteristics of the surveyed parents

\begin{tabular}{|c|c|c|}
\hline \multirow{2}{*}{$\begin{array}{l}\text { Demographic } \\
\text { characteristics }\end{array}$} & \multicolumn{2}{|c|}{ Total number of respondents $(\mathrm{N}=150)$} \\
\hline & $\mathbf{N}$ & $\%$ \\
\hline \multicolumn{3}{|l|}{ Gender } \\
\hline Male & 62 & 41.3 \\
\hline Female & 88 & 58.7 \\
\hline \multicolumn{3}{|l|}{ Age } \\
\hline$<30$ & 1 & 0.7 \\
\hline $30-39$ & 68 & 45.3 \\
\hline $40-49$ & 78 & 52.0 \\
\hline $50-59$ & 3 & 2.0 \\
\hline \multicolumn{3}{|l|}{ Education } \\
\hline Elementary school & 1 & 0.7 \\
\hline High school & 66 & 44.0 \\
\hline High school & 9 & 6.0 \\
\hline Faculty & 59 & 39.3 \\
\hline Master of Science & 10 & 6.7 \\
\hline Doctor of Science & 5 & 3.3 \\
\hline \multicolumn{3}{|l|}{ Marital status } \\
\hline Married & 132 & 88.0 \\
\hline Divorced & 13 & 8.7 \\
\hline Unmarried & 2 & 1.3 \\
\hline Divorced & 1 & 0.7 \\
\hline Widow / Widower & 2 & 1.3 \\
\hline
\end{tabular}

Parents of both sexes participated in the survey, and mothers were numerically dominant (88; $58.7 \%$ ). More than $97 \%$ of the surveyed parents belonged to the age range of 30 to 49 years. The largest number of surveyed parents had secondary education ( $44 \%$ ), but the number of university-educated parents was also very high (39.3 $\%)$. In $88 \%$ of cases, these were, at least formally, standard marriages.

Table 2: Basic socio-economic characteristics of the surveyed families

\begin{tabular}{|c|c|c|}
\hline \multirow{2}{*}{$\begin{array}{l}\text { Socio-economic } \\
\text { characteristics }\end{array}$} & \multicolumn{2}{|c|}{ Total number of respondents $(\mathrm{N}=150)$} \\
\hline & $\mathbf{N}$ & $\%$ \\
\hline \multicolumn{3}{|l|}{ Property status of the family } \\
\hline Satisfactory & 120 & 80.0 \\
\hline Somewhat satisfying & 29 & 19.3 \\
\hline Unsatisfactory & 1 & 0.7 \\
\hline \multicolumn{3}{|c|}{ The environment where they live } \\
\hline City & 118 & 78.7 \\
\hline Suburban & 32 & 21.3 \\
\hline Rural & 0 & 0.0 \\
\hline \multicolumn{3}{|c|}{ Number of children in the family } \\
\hline One & 23 & 15.3 \\
\hline Two & 87 & 58.0 \\
\hline Three or more & 40 & 26.7 \\
\hline \multicolumn{3}{|l|}{ Family type } \\
\hline Extended (2 generations) & 16 & 10.7 \\
\hline Family with 1 parent & 19 & 12.7 \\
\hline A family with both parents & 115 & 76.7 \\
\hline
\end{tabular}

Of the total number of respondents, 120 (80\%) thought that household income is satisfactory. Almost the same percentage of families lived in urban areas, and the rest (21.3\%) were located in 
suburban settlements. The largest percentage of families had two children (58\%), three or more children also had an enviable percentage of respondents (26.7\%). In most cases (76.7\%) these were families with both parents.

Table 3: Basic characteristics related to the procurement of a school bag

\begin{tabular}{ccc}
\hline \multirow{2}{*}{ School bag } & \multicolumn{2}{c}{ Total number of respondents (N = 150) } \\
& $\mathbf{N}$ & $\%$ \\
\hline Participant in election ${ }^{1}$ & & \\
\hline Mother & 93 & 62.0 \\
\hline Father & 31 & 20.7 \\
\hline A child & 90 & 60.0 \\
\hline The others & 2 & 1.3 \\
\hline Method of procurement ${ }^{2}$ & & \\
\hline Shop & 146 & 97.4 \\
\hline Via the Internet & 2 & 1.3 \\
\hline From family members (used) & 2 & 1.3 \\
\hline From a friend (used) & 0 & 0.0 \\
\hline Other & 0 & 0,0 \\
\hline
\end{tabular}

(1) possible multiple choice, percentages of individual answers exceed $100 \%$ (2) there is a possibility of only one answer, the total percentage is $100 \%$

A high percentage of mother and child were involved (62\% and $60 \%$, respectively) in the purchase of a school bag, and the fathers were involved in the purchase of only one in five children (31; $20.7 \%)$.

When it comes to participants in the selection of school bags, in 99 cases $(66.0 \%)$ only one of the above persons participated in the selection, in $37(24.7 \%) 2$ of the above persons participated in the procurement, in 13 (8.7\%) cases of 3 per-

Table 4: Type and basic characteristics of the school bag that children have

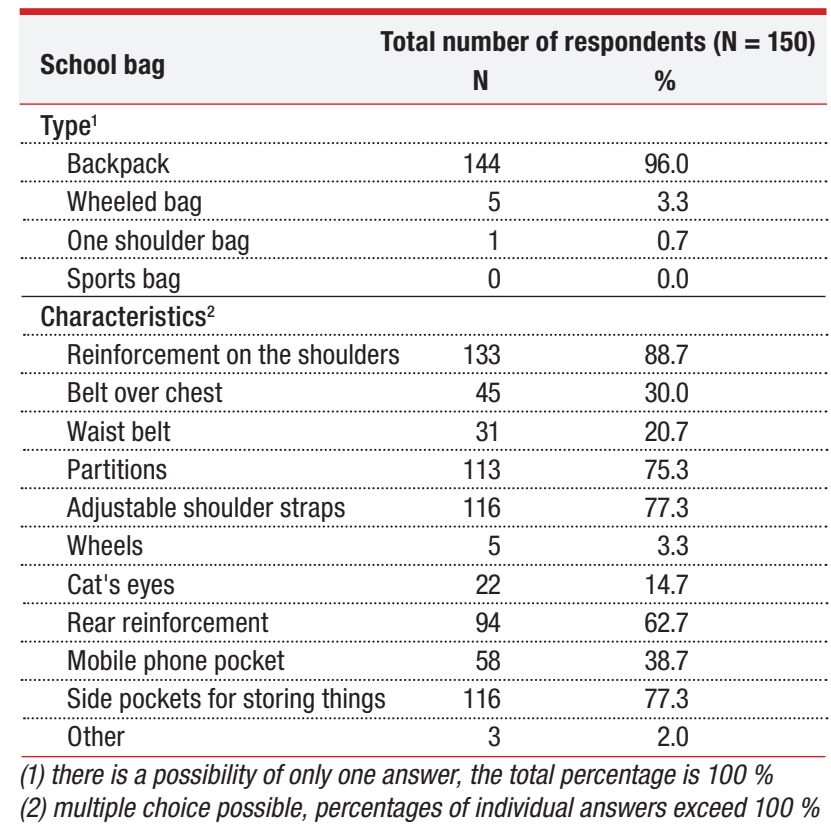

sons and only in 1 case $(0.7 \%)$ all 4 listed persons (data are not shown in the table).

School bags were predominantly procured in stores $(97.4 \%)$ and only sporadically via the Internet or by downloading used bags from other family members $(2.6 \%)$.

The dominant type of school bag purchased was the backpack model (96\%), and only sporadically the wheeled bag (3.3\%) (Table 4).

Among the characteristics that the purchased school bags had, according to their high representation, stand out reinforcement on the shoulders (88.7\%), adjustable shoulders (77.3\%) and side pockets for storing things (77.3\%).

Table 5 shows the desirable characteristics that a school bag must meet (left) and the real situation achieved by purchasing school bags (right). In a very small number of cases (15 school bags; $10 \%$ ), the basic criteria was fully met.

Table 5: Conformity of desired and realised characteristics of school bags

\begin{tabular}{ccc}
\hline School bag & $\begin{array}{c}\text { The presence of all } \mathbf{6} \\
\text { desired characteristics }\end{array}$ \\
\hline Minimum of desired characteristics & No & Yes \\
\hdashline Reinforcement on the shoulders & $135(90 \%)$ & $15(10 \%)$ \\
\hdashline Belt over chest & \\
\hline Waist belt & $\chi^{2}=245.45$ \\
Adjustable shoulder straps & $p<0.001$ \\
\hline Rear reinforcement & \\
\hline Side pockets for storing things & \\
\hline
\end{tabular}

Using the Chi-squared test $\left(\chi^{2}=245.45 ; \mathrm{p}<0.001\right)$, a significant difference between the desired and the achieved result was completely statistically proven. In the remaining number of cases (90\%), there is an absence of at least one or more desired characteristics.

A detailed analysis of the data from the Table 4 revealed that in most cases, the purchased school bags lack 2 characteristics (chest belt and waist belt are present in only $30 \%$ and $20.7 \%$, respectively) of purchased school bags.

Ranking was done according to the protocol: 1-Very important; 2-Important; 3-Not very important; 4-It doesn't matter at all; 5-I don't know. The graph presents mean values and standard deviations. 
Based on the stated ranking, it is clear that the answers with the lowest average grades indicated the fact of the importance of that characteristic of the school bag. In contrast, characteristics that were of very little importance to parents (or did not know enough about it), during the selection of the school bag, had the highest average grades (mostly above 3, dashed line) (Figure 1).

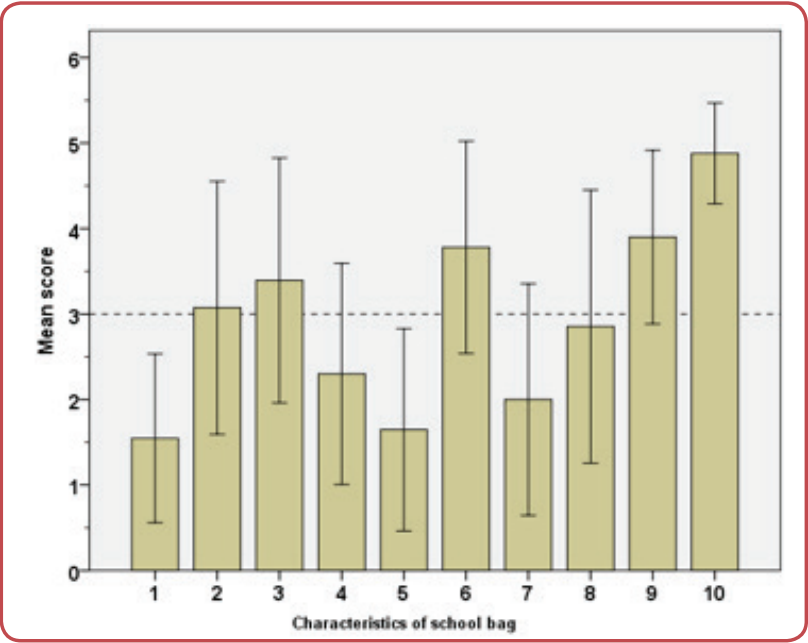

Figure 1: Parents' opinions on the importance of the characteristics that a school bag should have

1 - Shoulder reinforcement; 2 - Chest belt; 3- Waist belt; 4 - Partitions; 5 - Adjustable shoulder straps; 6 - Wheels; 7 - Reinforcement on the back of the bag; 8 - Cat's eyes; 9 - Mobile phone pocket; 10 - Other; Bars represent standard deviation of the mean;

In general, (Figure 1) most parents did not know the answer ( $94 \% ; n=141)$. Parents considered that the most important characteristics that a school bag should have are reinforcement on the shoulder straps $64.7 \%(\mathrm{n}=97)$, adjustable shoulders $65.3 \%(n=98)$ and reinforcement on the back of the bag $49.3 \% n=74$ ). Most of the other characteristics (average grades close to 3 or higher) were rated by the parents as slightly important or unimportant. A relatively small number of parents $28 \%(n=42)$ considered it very important that the school bag has features as a measure of safety and security when moving.

The largest number of parents (36.7\%) estimated that a filled school bag must be lighter than $10 \%$ of body weight, in a slightly lower percentage (35.3\%) the answer was related to the assessment that $5 \%$ is the limit weight of a filled school bag.

Most parents did not receive information about the school bag, $77.3 \%(\mathrm{n}=116)$. Vendors $11.3 \%$ $(n=17)$, other parents and friends $9.3 \%(n=14)$ were the main source of information before purchasing a school bag.
Table 6: Parents' assessment of the importance of school bag weight

\begin{tabular}{|c|c|c|}
\hline \multirow{2}{*}{ School bag } & \multicolumn{2}{|c|}{ otal number of respondents $(N=150)$} \\
\hline & $\mathbf{N}$ & $\%$ \\
\hline \multicolumn{3}{|l|}{ Weight ${ }^{1}$} \\
\hline Less than $5 \%$ of the child's weight & 53 & 35.3 \\
\hline $12 \%$ of the child's weight & 3 & 2.0 \\
\hline Less than $10 \%$ of the child's weight & 55 & 36.7 \\
\hline Less than $20 \%$ of the child's weight & 4 & 2.7 \\
\hline Less than $15 \%$ of the child's weight & 9 & 6.0 \\
\hline There is no standard bag weight & 16 & 10.7 \\
\hline Other & 10 & 6.7 \\
\hline
\end{tabular}

(1) there is a possibility of only one answer, the total percentage is $100 \%$

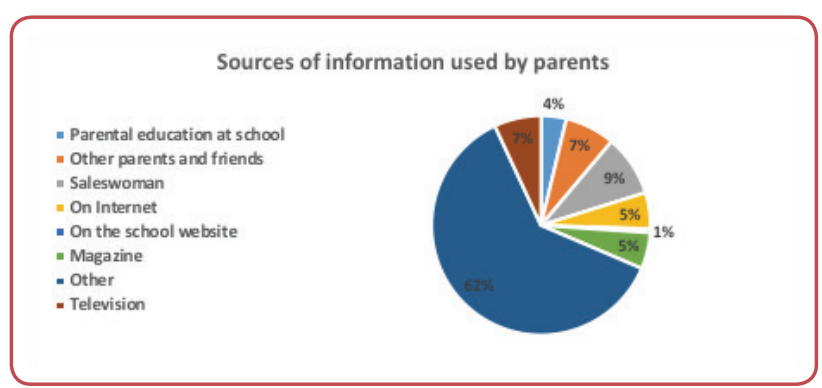

Figure 2: Sources of information used by parents

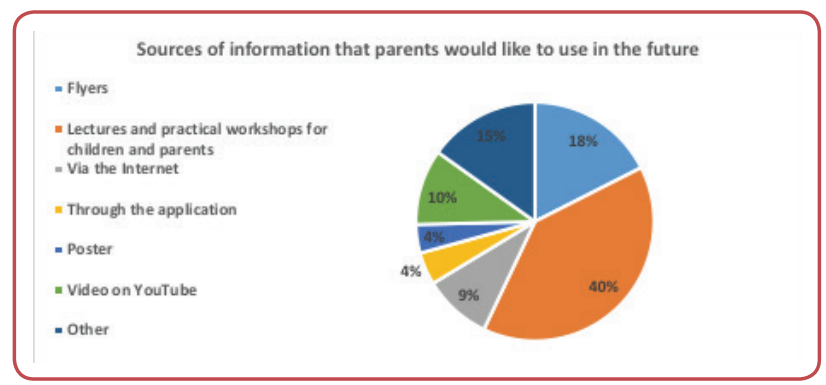

Figure 3: Source of information that parents would like to use in the future

A large number of $54 \%(n=81)$ of parents in the future would like to receive information about the school bag through lectures and practical workshops for children and parents, $24 \%$ (n = 36) written materials and video platforms $14 \%$ $(n=21)$.

\section{Discussion}

A large number of previous researches on the topic of carrying a school bag for school-age children have been focused on the identification of risk factors that are related to weight, back curvature, the presence of pain, exhaustion and the appearance of fatigue using statistical indicators. ${ }^{20-25}$ However, a small number of authors considered that the role of parents in solving this problem is crucial $^{26-28}$ and that it can significantly contribute to ensuring unhindered growth and development during the child's educational process. 
The aim of the study was to examine how much parents are informed about the school bag and which specifications are crucial when choosing a school bag for their children. 150 parents participated in the research, $54 \%$ female $(n=81)$ and 46 $\%$ male $(n=69)$. The largest number of parents belonged to the age structure between $40-49$ years $52 \%(n=78)$. Within the professional structure of female respondents, the highest percentage was with undergraduate education $40.7 \%(n=61)$ and male with secondary education $54 \%(n=81)$. The authors of Das and Goswami (2020) in the conclusion of their study reported that the educational qualification of parents acts as a major factor in raising awareness in children and that there are some differences in their views regarding the weight of a school bag. Lower educated parents ignored this problem and did not have enough knowledge about the harmfulness of a school bag, which is in line with the findings of this study. ${ }^{27}$ The analysis of the family structure showed that the largest percentage of children lived with both parents - $76.7 \%(\mathrm{n}=132)$, most often the families of respondents with two children were 57.3 $\%(\mathrm{n}=85)$, three or more children also had an enviable percentage of respondents $(26.7 \%)$ whose income was satisfactory 120 (80\%), of the total number of respondents, statistically, the survey most often covered the first child at birth $63.3 \%$ ( $\mathrm{n}=95$ ). This statement is important, because the attitude and knowledge that parents possess will certainly be applied to their younger children.

In $62 \%$ of cases, the mother and in $60 \%$ of cases the child participated in the selection of the school bag. In $97.4 \%$ of cases, the school bag was purchased in stores. The knowledge gained in this study is important, because greater information of parents enables adequate choice of school bag and reduces the possibility of marketing tricks and influence on consumers when choosing the desired product such as a school bag. A small percentage of children in this sample had a school bag on wheels (3.3\% of students), which indicates that parents do not consider the most suitable bag for a child to be a good choice. In accordance with the findings of previous studies, the backpack is the most common bag used by children, $96 \%, 28,29$ whose characteristics in $88.7 \%$ had a reinforcement on the straps, $75.3 \%$ adjustable straps, 62.7 $\%$ and side pockets for disposal of items by 77.3 $\%$. Their children's school bag had a number of satisfactory characteristics and the results were in line with the results of other studies. ${ }^{30,31}$
Parents' knowledge of the importance of the specifications that a school bag should have was satisfactory. In most cases, $64.7 \%(n=97)$ of parents consider it very important that the straps on the bag have reinforcement, $65.3 \%(\mathrm{n}=98)$ adjustable and $49.3 \%(n=74)$ reinforcement from the back foreign bags. Only $30.7 \%(n=46)$ of parents considered it important that a school bag should have a belt over the chest and $20.7 \%(n=31)$ a belt over the waist. The results of this study show that parents' knowledge is unsatisfactory and that the belt over the chest and waist helps distribute the load, which is in line with previous findings of other studies and the importance of health promotion and application and safety of school bags to reduce the incidence of pain in students. ${ }^{31}$ Significantly small number of children, $14 \%(n=22)$ had a cat's eye on a school bag and also a small number of parents, $28 \%$ ( $n=42$ ) considered it important that the school bag had features as a measure of safety and security when moving. This statement is important and indicates that parents' awareness of safety and security measures when moving is low. The largest number of parents, $36 \%(n=55)$ believed that the weight of the school bag should be less than $10 \%$ of body weight and $35.3 \%(n=53)$ that the weight of the school bag should be less than $5 \%$ of body weight, which indicates that parents were satisfactorily informed about the recommended weight of the school bag, which was stated in a study conducted among 616 parents in Saudi Arabia, which reported that only $37.6 \%$ of fathers and $28.9 \%$ of mothers knew the ideal weight of the school bag. ${ }^{34}$

Most parents did not receive information about the school bag, $77.3 \%(\mathrm{n}=116)$. Salespeople $11.3 \%$ $(\mathrm{n}=17)$, other parents and friends $9.3 \%(\mathrm{n}=14)$ were the main source of information before purchasing a school bag. Interestingly, $54 \%(n=81)$ of parents have chosen hands-on workshops to adopt new information about the school bag. A small number of parents, $24 \%(\mathrm{n}=36)$ considered written materials and video platforms (14\% $(n=21)$ ) a good way to gain knowledge and information about the school bag as a teaching tool. The results of this study contradict the results of a study that reported that parents considered written materials as the best source of knowledge acquisition. ${ }^{19}$

So far, no studies on information and attitudes of parents about the school bag have been pub- 
lished in the Republic of Srpska and the Federation of Bosnia and Herzegovina. The parents' survey was conducted within the project for the development of a doctoral thesis, to obtain more detailed information on wearing habits and characteristics of school bags that may affect further physical development of children.

\section{Conclusion}

Most parents, $77.3 \%(\mathrm{n}=116)$ did not receive information about the school bag. Parents demonstrated satisfactory knowledge of the appropriate type of school bag and the allowable weight that the school bag should have. Parents' knowledge was satisfactory about the specifications that a school bag should have, but in $90 \%$ of cases there was the absence of at least one or more desired characteristics of their children's school bag. In most cases $(70 \%$ and $79.3 \%$ ), school bags lack 2 characteristics (chest belt and waist belt) that help distribute the load during use. Although, we live in the age of information technology, a large number, $54 \%(n=81)$ of parents in the future would like to get information about the school bag through lectures and practical workshops for children and parents. A small number of parents, $24 \%(\mathrm{n}=36)$ considered written materials and video platforms, $14 \%(\mathrm{n}=21)$ as a good way to gain knowledge and information about the school bag as a teaching tool. Preventive programs enable children and parents to adopt new values, skills for the most correct and uninterrupted functioning of the body in performing daily life activities, applications and safety of students during the use of school bags. Greater parental awareness allows for adequate school bag selection and reduces the possibility of marketing gimmicks and influencing consumers when choosing a desired product, such as a school bag. Parents have an important role to play in ensuring the unhindered growth and development during the child's educational process and in strengthening children's awareness and supervision about the proper use of the school bag.

\section{Acknowledgements}

None.

\section{Conflict of interest}

None.

\section{References}

1. Azabagic S, Spahic R, Pranjic N, Mulic M. Epidemiology of musculoskeletal disorders in primary school children in Bosnia and Herzegovina. Mater Sociomed 2016;28:164-7.

2. Dolphens M, Vansteelandt S, Cagnie B, Vleeming A, Nijs J, Vanderstraeten G, et al. Multivariable modeling of factors associated with spinal pain in young adolescence. Eur Spine J 2016;25(9): 2809-21.

3. Picavet HS, Berentzen N, Scheuer N, Ostelo RW, Brunekreef B, Smit HA, et al. Musculoskeletal complaints while growing up from age 11 to age 14: the PIAMA birth cohort study. Pain 2016;157.

4. Hu JMY, Jacobs K. Backpack usage and self-reported musculoskeletal discomfort in university students. In Proceedings of the human factors and ergonomics society annual meeting sage CA: Los Angeles, CA: SAGE Publications 2008;52 (9):702-5.

5. Janakiraman B, Ravichandran H, Demeke S, Fasika S. Reported influences of backpack loads on postural deviation among school children: A systematic review. J Educ Health Promot 2017;6:41.

6. Pascoe DD, Pascoe DE, Wang YT, Shim DM, Kim CK. Influence of carrying book bags on gait cycle and posture of youths. Ergonomics 1997;40(6):631-40.

7. Skoffer B. Low back pain in 15-to 16-year-old children in relation to school furniture and carrying of the school bag. Spine 2007;15:32(24): E713-7.

8. Mwaka ES, Munabi IG, Buwembo W, Kukkiriza J, Ochieng J. Musculoskeletal pain and school bag use: a crosssectional study among Ugandan pupils. BMC research notes 2014;9:7(1):222.

9. Perrone M, Orr R, Hing W, Milne N, Pope R. The impact of backpack loads on school children: A critical narrative review. Int J Environ Res Public Health 2018 Nov 12;15(11):2529.

10. Mackie H W, Legg SJ. Postural and subjective responses to realistic schoolbag carriage. Ergonomics 2008;51(2):21731.

11. Pau M, Kim S, Nussbaum MA. Does load carriage differentially alter postural sway in overweight vs. normal-weight schoolchildren? Gait Posture 2012 Mar;35(3):378-82.

12. De Paula AJF, Silva JCP, Paschoarelli LC, Fujii JB. Backpacks and school children's obesity: challenges for public health and ergonomics 2012. Work, 41(Supplement 1):900-6. 
13. Pau M, Leban B, Pau M. Alterations in the plantar pressure patterns of overweight and obese schoolchildren due to backpack carriage. J Am Podiatr Med Assoc 2013 JulAug;103(4):306-13.

14. Cavallo CM, Hlavaty TM, Tamase MG. A pilot study for the development of a primary prevention program: What is the average weight of a fourth grader's backpack? Work 2003;20(2):137-58.

15. Dianat I, Karimi MA. Association of parental awareness of using schoolbags with musculoskeletal symptoms and carrying habits of schoolchildren. J Sch Nurs 2014 Dec;30(6):440-7.

16. Association AOT. Backpack-Related, 2014. [Internet]. [Cited 2021-Jun-02]. Available from: https://www.aota. org/ConferenceEvents/Backpack-Safety-AwarenessDay/ Handouts.aspx.

17. Samaržija D V, Mišigoj-Duraković M. Pouzdanost hrvatske verzije upitnika za procjenu ukupne razine tjelesne aktivnosti djece mlađe školske dobi. Hrvatski športskomedicinski vjesnik 2013;28(1):24-32.

18. Kowalski K C, Crocker P R, Donen R M. The physical activity questionnaire for older children (PAQ-C) and adolescents (PAQ-A) manual. College of Kinesiology, University of Saskatchewan 2004;87(1):1-38.

19. Dockrell S, Jacobs K, Byrne J, Gleeson E, Kelly S, Moore C, Blake C. Parental awareness of schoolbag carriage: a comparative study of Irish and United States parents. Work 2017;58(2):85-93.

20. Chen YL, Nguyen HT, Chen Y. Influence of school bag loads and carrying methods on body strain among young male students. Int J Ind Ergon 2021;82:103095.

21. Ismaeel FT, Dawood WF, Ibraheem NM, Mawlood AF, Mahmood RJ. Evaluation the relation between school bag weight and backache among primary school pupils in Tikrit City. Medico Legal Update 2020;20(1):278-83.

22. Al Shahry FS, Almahmoud HA, Alhujairy RI, Aljohi KK. Effect of school bags on body mechanics among Saudi children. Biosci Biotech Res Comm 2018;11:402-8.

23. Rezapur-Shahkolai F, Gheysvandi E, Tapak L, Dianat I, Karimi-Shahanjarini A, Heidarimoghadam R. Risk factors for low back pain among elementary school students in western Iran using penalized logistic regression. Epidemiol Health 2020;42:e2020039.

24. Assiri A, Mahfouz A A, Awadalla N J, Abolyazid AY, Shalaby M. Back pain and schoolbags among adolescents in Abha
City, Southwestern Saudi Arabia. Int J Environ Res Public Health. 2019 Dec 18;17(1):5.

25. Chalise G D, Sherpa S, Bharati M, Ambu K C. Parental awareness about school backpack, weight carried by their children and related musculoskeletal problems. Med J Shree Birendra Hosp 2020;19(2):97-102.

26. Sukartini T, Ariyani M D, Yasmara D. Knowledge and actions about safety in the use of backpacks not related to back pain complaints in primary school students. EurAsian Journal of BioSciences 2020;14(2):2751-5.

27. Das D, Goswami D. A study on the parental awareness on the heavy weight school bag of primary school children in Guwahati City. Int J Psychosoc Rehabilitation 2020;24(04).

28. Dianat I, Karimi MA. Association of parental awareness of using schoolbags with musculoskeletal symptoms and carrying habits of schoolchildren. J Sch Nurs 2014;30(6):440-7.

29. Magrabi NME, Mahmoud SRM, Yousef YE. Awareness of parents about school backpack and its related musculoskeletal disorders in Assiut City. J Nurs Health Sci 2015;4(6):5-11.

30. Javadivala Z, Allahverdipour H, Dianat I, Bazargan M. Awareness of parents about characteristics of a healthy school backpack. Health Promot Perspect 2012;2(2):16672.

31. Patil MA, Sumana S, Shagale N. Awareness of parents about characteristics and carrying habits of backpacks and its comparison with behavioural practices of their children. Int J Pediat Res 2016;3(3):173-9.

32. Javadivala Z, Allahverdipour H, Dianat I, Bazargan M. Awareness of parents about characteristics of a healthy school backpack. Health Promot Perspect 2012;2(2):16672.

33. Sukartini T, Ariyani MD, Yasmara D. Knowledge and actions about safety in the use of backpacks not related to back pain complaints in primary school students. Eurasia J Biosci 2020;14(2):2751-5.

34. Alsiddiky A, Alatassi R, Alsaadouni F N, Bakerman K, Awwad W, Alenazi A, Alyaseen H. Assessment of perceptions, knowledge, and attitudes of parents regarding children's schoolbags and related musculoskeletal health. J Orthop Surg Res 2019 Apr 27;14(1):113. doi: 10.1186/s13018-0191142-9. 